\title{
Influence of Motor Starting on The Operating Characteristics of Diesel Generator Sets
}

\author{
Guogang Wei, ${ }^{1,}$, Shiyu Sun ${ }^{2}$,Jinning Liu $^{3}$ \\ 1,2,3 Ordnance Engineering College,Shijiazhuang 050003,China. \\ aweiguogang@163.com
}

Keywords: Motor,diesel generator sets,fluctuation ratio,THD

\begin{abstract}
In view of the serious impact on the starting process of the motor, the simulation experiment is conducted to study the influence of the diesel generator sets on steady operation.The diesel generator output voltage and frequency waveforms were analyzed by transient adjustment rate and the fluctuation rate calculation of voltage and frequency, grasp the change range of voltage and frequency;through the analysis of the total harmonics distortion(THD), to understand the degree of distortion of the waveform. The influence characteristics of motor starting to diesel generator sets are mastered through the simulation experiments.
\end{abstract}

\section{Introduction}

Motor starting will produce a larger starting current that is about 5-7 times the rated current,which cause line voltage drop.The motor starting current will cause the fluctuation of the output voltage and frequency of diesel generator sets when the diesel generator sets capacity is small,to cause great harm to oneself and other electric equipment.

On the motor starting and diesel generating units are subjected to impact load.Harm and influence analysis of generator sets power quality caused by nonlinear and impact load,the control measures have been putted forward[1].An adaptive technique based on the mean square relative error which can reduce the signal estimation is proposed to calculate the harmonics and inter harmonics.The output voltage distortion of PWM inverter with LC filter is analyzed by the method of linear approximation.An artificial neural network based approach to estimate the degree of distortion of voltage and current in a nonlinear load[2-4].In view of the current phenomenon of the diesel generator, the method of controlling the stability of the power supply system is put forward through reasonable energy storage control[5].

In this paper, the operation characteristics of the diesel generator set with impact load is analyzed, and the system simulation model is built by using Matlab/Simulink simulation software.Volatility and waveform distortion of output voltage and frequency of the diesel generator sets and the waveform distortion are analyzed, and the effects of different load conditions are compared.

\section{System Simulink Model}

Diesel generator sets model can be divided into three parts according to the function: diesel engine and speed control system, excitation voltage regulation system and synchronous generator.The simulation experiment using the diesel generator sets rated power $50 \mathrm{KW}$, rated speed $1500 \mathrm{rad} / \mathrm{min}$, rated output line voltage $400 \mathrm{~V}$, and frequency $50 \mathrm{~Hz}$ as shown in figure 1.

The motor directly used the existing model of the asynchronous motor simulation, due to the structure of squirrel cage induction motor is simple, easy starting, small volume, high efficiency and power factor.Squirrel cage induction motor rated power $22 \mathrm{KW}$, rated speed $3000 \mathrm{rad} / \mathrm{min}$, rated line voltage $380 \mathrm{~V}$, and frequency $50 \mathrm{~Hz}$ as shown in figure 1. 


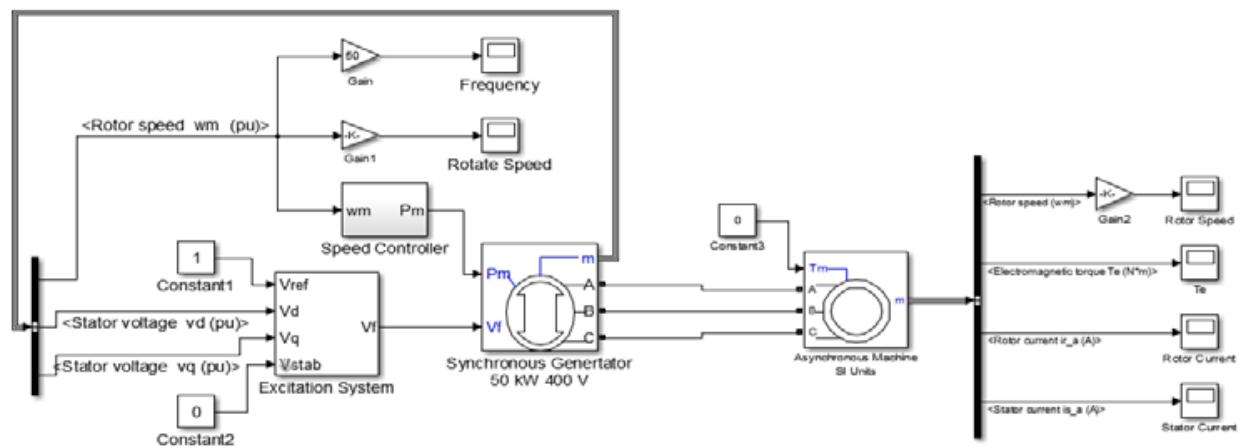

Fig. 1 System integrated simulation model

\section{Experimental Results and Analysis}

According to the actual parameters of the system model and system, build a system model based on MATLAB/SIMULINK platform.No-load experiment of motor has been done at first,after are the motor with different load starting under load experiments.Based on the simulation results, the effects of motor with different load of the output voltage and frequency of the diesel generator sets are analyzed.Simulation using ode23tb algorithm, the simulation time is $2.5 \mathrm{~s}$.

\section{Frequency Variation}

This simulation experiment the diesel generator set only on the motor power supply,with motor no-load start.At the 1s time starting motor, frequency waveform as shown in figure 2.

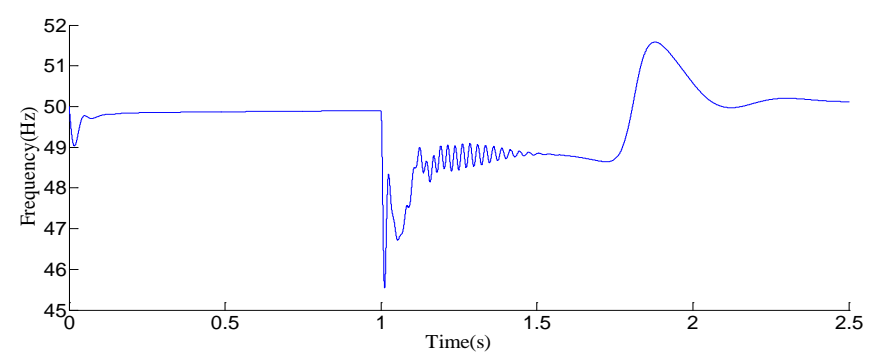

Fig. 2 Output frequency waveform

Figure 2 reflects the changes in the frequency of the motor starting process: at the moment of 1s motor suddenly access, mechanical torque is less than the electromagnetic torque of the motor ,only by reducing the speed of the generator to maintain mechanical torque constant, caused a decline in the output frequency of the output frequency. When the output power of diesel engine and mechanical torque of the generator increases, rising start speed, and the output frequency increases.In the process of motor acceleration, the power demand is basically the same. The output power and the speed of the diesel generating set are basically unchanged.Motor rotor speed to achieve the rated speed will not be maintained at the rated speed, and the need to go through a short period of oscillation adjustment process. At the same time, the output of the diesel generator is in conjunction with the regular variation. After the oscillation adjustment, the operating frequency is rated at the same time.

In order to understand the variation range of the output frequency of the diesel generator set in the starting process of the motor, the transient frequency adjustment rate can be obtained.The calculation formula of transient frequency regulation rate:

$$
\delta_{f s}=\frac{f s-f}{f} \times 100 \%
$$

where $f$ is rated frequency; $f s$ is the maximum and minimum value of instantaneous frequency.

When $f s \min =43.70 \mathrm{~Hz}, f s \max =51.58 \mathrm{~Hz}$, transient frequency regulation rate: $\delta_{\uparrow s 1}=-12.60 \%, \delta_{\uparrow \mathrm{s} 2}=+3.02 \%$.

In order to get the power fluctuation, the frequency fluctuation can be reflected by calculating the frequency fluctuation. The calculation formula of frequency fluctuation: 


$$
\delta_{f B}=\frac{f_{B \max }-f_{B \min }}{f_{B \max }+f_{B \min }} \times 100 \%
$$

where $f_{B \min }, f_{B \max }$ are the maximum and minimum value of frequency.

When $f_{B \min }=45.54 \mathrm{~Hz}, f_{B \max }=51.58 \mathrm{~Hz}$, Frequency fluctuation: $\delta_{f B}=8.20 \%$.

\section{Current and Voltage Variation}

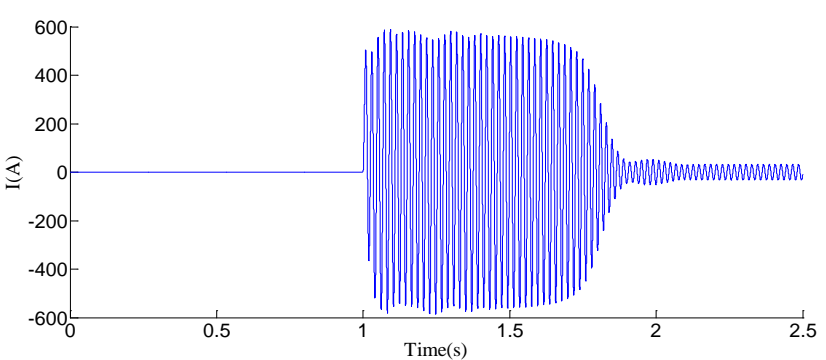

(a).Output single phase current waveform

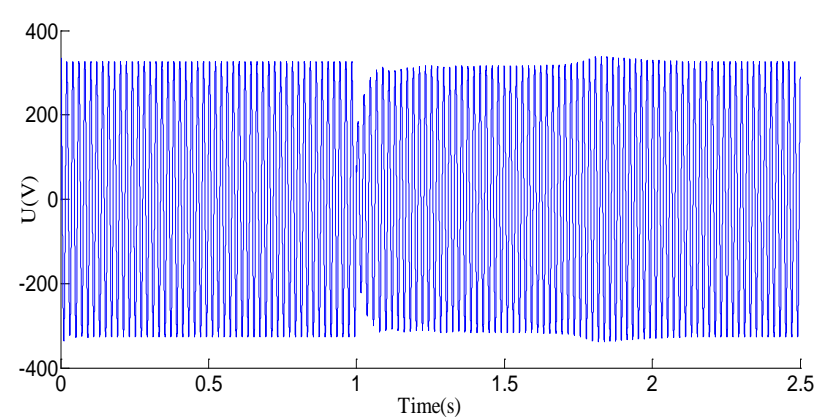

(c).Output single phase voltage waveform

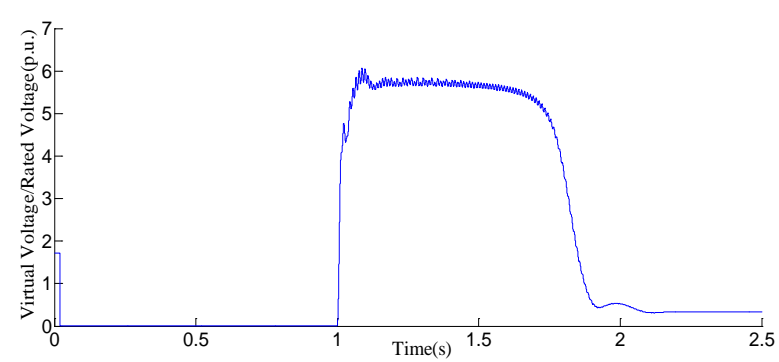

(b).Output current variation curve

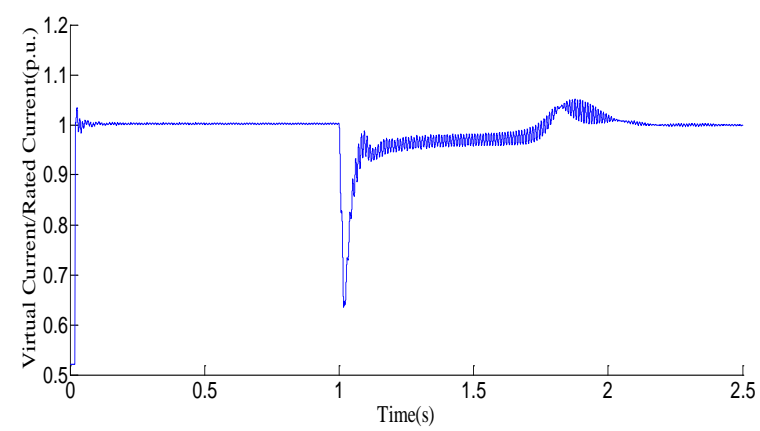

(d).Output voltage variation curve

Fig. 3 Output current and voltage waveform

Figure 4 (a) for the current waveform, the access time at 1s, The rotating magnetic field generated by the stator motor access moment relative to the rotor has relatively great speed, rotor magnetomotive force and produce a large current, causing the starting current is large, the maximum amplitude current is 580A.In the acceleration phase of the motor, the starting current is kept at about 550V. When the motor reaches the rated speed, the stator and rotor current is reduced, and the output current of the diesel generator is finally stabilized at 33A. The maximum value of the starting current of the motor is 6 times of the rated current, as shown in Figure 4 (b).

Figure 4 (c) for the voltage waveform, the access time at 1s, the voltage will occur instantaneously suddenly decreased greatly, the maximum amplitude decreases to about 220V.After the motor acceleration process, voltage amplitude and then gradually stabilized at about $310 \mathrm{~V}$. when the motor speed reaches and exceeds the rated speed,the voltage maximum amplitude can reach 335V. After a short oscillation adjustment, the diesel generator set to maintain the rated voltage run. Figure 4 (d) in the process of motor starting unit bus voltage is the lowest rating of $64.16 \%$, after a period of time in the ratings of around $96 \%$, voltage only in the motor moment of access have larger voltage drop, then accelerate the process of the bus voltage is small.

The calculation formula of transient voltage regulation rate:

$$
\delta \text { Us }=\frac{U_{s}-U}{U} \times 100 \%
$$

where $U$ is rated voltage; $U s$ is the maximum and minimum value of instantaneous voltage.

When $U_{s \min }=273.5 \mathrm{~V}$, $U_{s \max }=414.1 \mathrm{~V}$,transient voltage regulation rate: $\delta$ uS $1=-31.63 \%, \delta$ uS $2=+3.52 \%$.

The calculation formula of voltage fluctuation rate:

$$
\delta_{U B}=\frac{U_{B \max }-U_{B \min }}{U_{B \max }+U_{B \min }} \times 100 \%
$$

where $U_{B \min }, U_{B \max }$ are the maximum and minimum value of voltage.

When $U_{B \min }=273.5 \mathrm{~V}, U_{B \max }=414.1 \mathrm{~V}$,voltage fluctuation rate: $\delta u_{B}=20.45 \%$. 


\section{Harmonic}

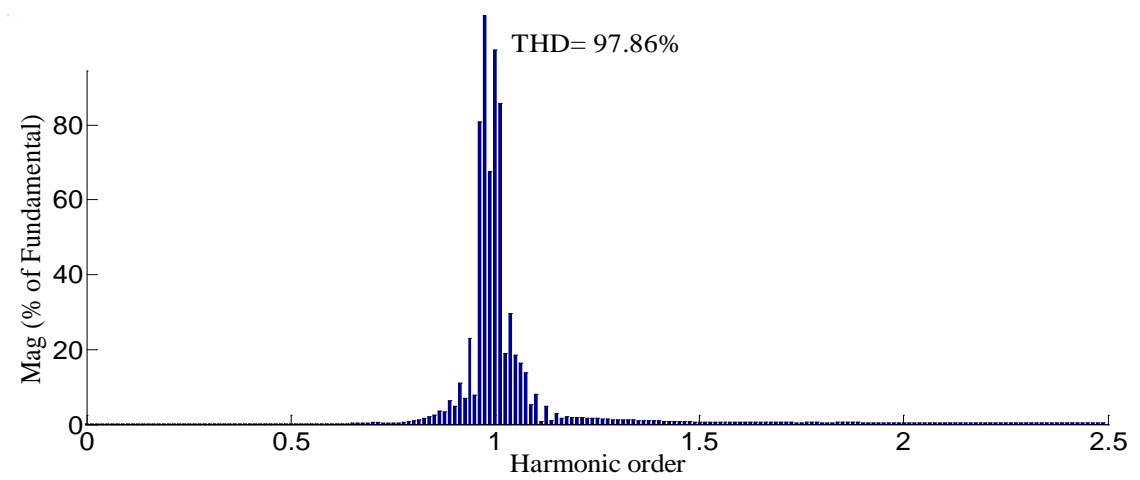

(a).Voltage harmonic content distribution

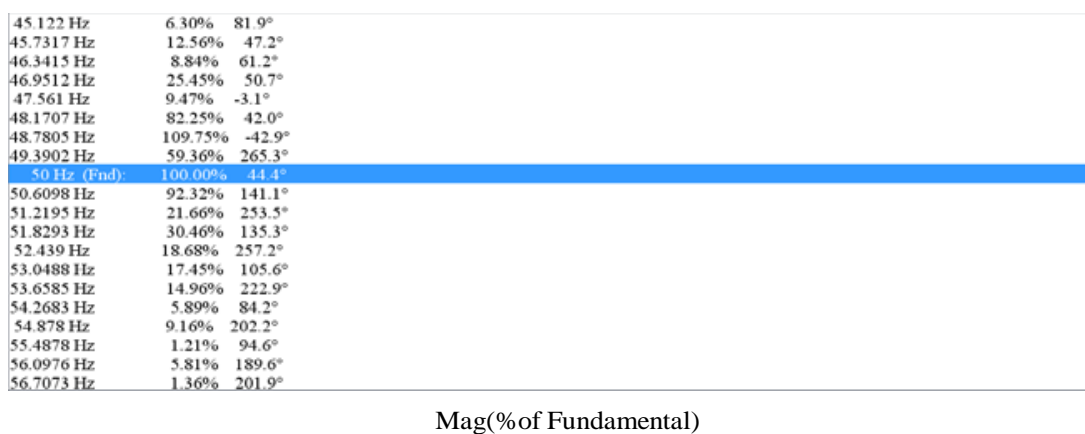

(b).Relative fundamental wave of voltage harmonics

Fig. 4 Voltage harmonic content diagram

It is can be seen from Figure 4 the total harmonic distortion rate of voltage is $T H D=97.86 \%$, during motor start-up the main harmonic components is focused on fundamental near the inter harmonics. In Figure 5 (b) can clearly see the relative fundamental wave of the inter harmonics, the impact of the maximum frequency value is $f=48.7805 \mathrm{~Hz}$, it is more than the fundamental wave, the other effects of the frequency of the main $46.9512 \mathrm{~Hz}, 48.1707 \mathrm{~Hz}, 49.3902 \mathrm{~Hz}, 50.6098 \mathrm{~Hz}, 51.8293 \mathrm{~Hz}$. It can be obtained that the distortion of the output voltage of the diesel generating set in the starting process of the motor is mainly due to the inter harmonics.

\section{Motor With Load Starting}

Effects of motor output voltage and frequency stability of diesel generator sets are obtained by adjusting the output mechanical torque of the motor with different load. Calculation of diesel generator output voltage and frequency of transient regulation and fluctuation rate, voltage harmonic distortion rate and the starting time, as shown in Table 1.

Table 1 Steady state index of electric motor with different load

\begin{tabular}{|c|c|c|c|c|c|c|c|c|}
\hline \multirow{2}{*}{$\begin{array}{c}\text { Power(p.u.) } \\
\text { Items }\end{array}$} & \multicolumn{2}{|c|}{$\delta_{f s}(\%)$} & $\delta_{f B}(\%)$ & \multicolumn{2}{|c|}{$\delta$ Us (\%) } & $\delta_{\text {UB (\%) }}$ & THD(\%) & $\begin{array}{c}\text { Start-up } \\
\text { Time(s) }\end{array}$ \\
\hline 0 & -12.60 & +3.02 & 8.20 & -31.63 & +3.52 & 20.45 & 97.86 & 1.6 \\
\hline 0.2 & -12.62 & +3.00 & 8.19 & -31.63 & +3.37 & 20.38 & 90.09 & 1.9 \\
\hline 0.4 & -12.60 & +2.94 & 8.16 & -31.66 & +3.25 & 20.34 & 93.89 & 1.95 \\
\hline 0.6 & -12.56 & +2.92 & 8.13 & -31.53 & +3.25 & 20.26 & 100.41 & 2.15 \\
\hline 0.8 & -12.58 & +2.94 & 8.15 & -33.62 & +2.85 & 21.55 & 127.80 & 2.25 \\
\hline 1 & -12.54 & +3.02 & 8.15 & -32.48 & +2.91 & 20.76 & 151.77 & 2.4 \\
\hline
\end{tabular}

The above table reflects the output voltage and frequency of the transient regulation rate and the 
fluctuation rate of the diesel generator sets is independent of the load of the motor.Diesel generator sets output voltage total harmonic distortion and motor load is related to the degree of load, the total harmonic distortion is caused by the greater rate of waveform distortion is more serious, but at no-load the total harmonic distortion is not according to the law of changes of load, the total harmonic distortion is relatively large, also cause waveform distortion the more serious. The starting time of the motor is related to the load of the motor, and the starting time increases with the increase of the load.

\section{Conclusion}

The motor in diesel generator sets under the simulation of starting, analysis for motor starting diesel generator sets output voltage and frequency of the impact, and compared with the change of output voltage and frequency fluctuation under load on the motor. Conclusions are as follows:

1) Motor caused by sudden output voltage and frequency as well as changes in volatility, the pressure drop is large, and the frequency fluctuation between $40 \sim 60 \mathrm{~Hz}$, extremely unstable. But the output voltage and frequency does not change with the increase of the load of the motor.

2) Motor start can cause serious distortion of the voltage waveform, which is caused by the distortion of the fundamental wave in the vicinity of the inter harmonics, and the distortion of the motor with the increase of load and become more serious.

Fund project:The National Natural Science Fund(51307184)

\section{References}

[1] Wenjie.Xu,Haitao.Liao,The influence of nonlinear load and impact load on the quality of power supply and the control measures,J.Mobile Power Supply and Vehicle,2014(3):26-27.

[2] Bracale A,Caramia P,Carpinelli G.Adaptive prony method for waveform distortion in power systems,J.International Journal of Electrical Power and Energy Systems,5,29(2007)371-379

[3] Nakamura Y,Funato H,Ogaswar S.Output voltage distortion analysis of PWM inverter with LC filter caused by device voltage drop,C.Power Conversion Conference.Nagoga:IEEE Press,2007:116-121

[4] Oleskovicz M,Lima M A A,Biasotto E,et al.Estimation of harmonic currents injected by nonlinear loads for a distorted power supply scenario using artificial neural networks,C.2012 IEEE $15^{\text {th }}$ International Conference on Hamonics and Quality of Power (ICHQP).Hongkong:IEEE Press,2012:457-562

[5] M.A. Tankari,M.B.Camara,B.Dakyo,et al.Use of U1-tracapacitors and Batteries for Efficient Energy Management in Wind-Disel Hybrid System,J.IEEE Trans.Sustainable Energy,2013,4(2):414-424.

[6] Guo Xiaoliang,Ma Lishang.The influence of high-capacity impact loads on the generator set,J.Electrical engineering and automation,2010,276(30):121-122. 